\title{
La democracia entre lo catastrófico y lo monstruoso
}

Hector Ariel Lugo (UNNE)*

https://orcid.org/0000-0002-6129-7499

\section{Resumen:}

Lo catastrófico y lo monstruoso siempre irrumpen intempestivamente, acontecen y quiebran con el orden establecido, dan un vuelco y ponen todo pies para arriba, obligan a mirar todo desde otro lugar que no estaba previsto. Ambos, son siempre temidos, excluidos por ser desconocidos, marginados porque se los asocia a la perdición, a la maldad y al advenimiento de penurias. Sin embargo, desde la lectura que propone Jacques Derrida de estos "conceptos", se verá que todo eso está sustentado en prejuicios, que buscan someter y ocultar algunas cuestiones que "incomodan". Entonces, es la comodidad y la seguridad, en lo ya conocido, sabido y probado, lo que lleva a vestir de monstruoso y catastrófico a todo lo que se desconoce, incierto e inquietante. En ese sentido, en el escrito se busca rastrear lo catastrófico y monstruoso desde algunas de las primeras obras de Derrida y vincularlo con lo por venir de la democracia.

Palabras clave: Monstruoso; Catastrófico; Democracia por venir.

\section{Abstract:}

\section{Democracy between the catastrophic and the monstrous}

Catastrophic and monstrous things always burst in unexpectedly, happen and break with the established order, turn everything upside down and force everything to be looked at from another place that was not foreseen. Both are always feared, excluded because they are unknown, marginalized because they are associated with perdition, evil and the advent of hardship. However, from the reading that Derrida proposes of these "concepts", it will be seen that all this is based on prejudices, which seek to submit and hide some issues that "make us uncomfortable". Then, it is comfort and security, in what is already known, known and proven, that leads to dressing everything that is unknown, uncertain and disturbing as monstrous and catastrophic. In this sense, the writing seeks to trace the catastrophic and monstrous from some of Derrida's early works and link it to what is to come from democracy.

Keywords: Monstrous; Catastrophic; Democracy to come.

* Professor de Filosofia - Universidad Nacional del Nordeste (UNNE), Argentina. Doutorando em Filosofia (UNNE); Mestre em Ciências Sociais e Humanas (UNNE). E-mail: arielhlugo@hotmail.com 


\section{Resumo:}

\section{A democracia entre o catastrófico e o monstruoso}

0 catastrófico e o monstruoso sempre irrompem de forma inesperada, acontecem e rompem com a ordem estabelecida, viram tudo de cabeça para baixo, obrigando-nos a olhar para tudo de outro lugar que não era previsto. Ambos são sempre temidos, excluídos porque são desconhecidos, marginalizados, porque estão associados à perdição, ao mal e ao advento das adversidades. Porém, a partir da leitura que Jacques Derrida propõe desses "conceitos", veremos que tudo isso se baseia em preconceitos, que buscam subjugar e ocultar algumas questões que "incomodam". Portanto, é o conforto e a segurança, naquilo que já é conhecido, conhecido e comprovado, que revestirá de monstruoso e catastrófico tudo o que é desconhecido, incerto e perturbador. Nesse sentido, a escrita busca traçar o catastrófico e monstruoso de algumas das primeiras obras de Derrida e vinculá-lo ao futuro da democracia.

Palavras-chave: Monstruoso; Catastrófico; Democracia porvir.

...si aún tiene que suceder algo, nada es menos seguro, hace falta que sea unpredictable...

(DERRIDA, 1994, p. 53-54)

En su Circonfesión, Derrida (1994, p. 52-59) ensaya una objeción revestida de cariño con respecto a la búsqueda de Bennington de poder comprender (encerrar) en una matriz su pensamiento. Jacques, le concede esa pretensión, junto con la de no citarlo, no sin dejar en claro y abiertamente la imposibilidad de tal proyecto, de reducción a una matriz e inclinándose hacia la aperturabilidad de lo por venir. En esa queja se deja percibir la obliteración de lo por venir que vendría dada desde algo concluido, desde una matriz que prescinda de nuevas inscripciones, un intento de eludir lo monstruoso de la democracia. En ese reproche tierno (realizado por Jacques, concediendo que hay un matriz) pero firme (escrito por Derrida, marcando que no se puede reducir a lo matricial), se podría ver la postura de Derrida con relación al por venir y monstruoso que siempre ponen en cuestión a la democracia.
Lo catastrófico y lo monstruoso siempre irrumpen intempestivamente, quiebran con el orden establecido, dan un vuelco y ponen todo pies para arriba, obligan a mirar todo desde otro lugar que no estaba previsto. Ambos, son siempre temidos, excluidos por ser desconocidos, marginados porque se los asocia a la perdición, a la maldad y al advenimiento de penurias. Sin embargo, desde la lectura que propone Derrida de estos "conceptos", se verá que todo eso está sustentado en prejuicios, que buscan someter y ocultar algunas cuestiones que "incomodan". Entonces, es la comodidad y la seguridad, en lo ya conocido, sabido y probado, lo que lleva a vestir de monstruoso y catastrófico a todo lo que se desconoce, incierto e inquietante.

En el presente trabajo, se desarrolla la crítica de Derrida al tratamiento que realizan Ferdinand de Saussure y Jean-Jacques Rousseau de lo catastrófico y monstruoso, rechazando la intención de los mismos de atribuir determinados rasgos negativos a lo extraño, desconocido y al(lo) otro.

Derrida desde una postura cercana a la de Walter Benjamin, sostiene que la catás- 
trofe sería necesaria para el cambio y el progreso, y considerarlo como algo pernicioso, es una postura política que busca perpetuar siempre lo mismo, evitar la disidencia y eludir lo diferente. Lo monstruoso, en esos casos, funcionaría como un armazón para protegerse de lo que está por fuera de la norma, que otorga tranquilidad contra lo diferente. La democracia por venir sería lo catastrófico por tender siempre al cambio y las decisiones cada vez más inclusivas, y a un mismo tiempo, sería monstruosa por no poder anticiparse, por irrumpir intempestivamente, por no estar reducida a norma alguna.

Es así que, desde sus primeras obras publicadas, Derrida arremete contra toda esa estrategia política que desechará toda nueva forma de entender cuestiones que están dadas como verdades perennes. Este trabajo de deconstrucción que realiza Derrida, no se ciñe únicamente a sus primeras publicaciones, sino que atraviesa toda su obra, muestra de ello es su último seminario $L a$ bestia y el soberano donde retoma la cuestión de lo monstruoso en clave de lo político. Por eso, se detiene, con tanta insistencia, sobre lo catastrófico y monstruoso en Rousseau y Saussure, para hacer evidente que ese rechazo a la escritura, es motivado por un gesto político, quizás, "el" gesto político que mantiene el orden, poder y control, y oculta todo lo que atenta contra ellos. Lo que no logran percibir, y lo demuestra Derrida, es que ese rechazo es vano, ya que en el interior mismo de ese gesto está lo catastrófico y lo monstruoso, que no se podrán librar de ellos, que estuvieron ahí desde el "origen", por ello, toda lucha que se realice colocándolos en una exterioridad, está condenada al fracaso.

La democracia es receptiva y trabaja con esos "conceptos" excluidos, ya que se mueve en lo acontecimental (DERRIDA, 2006), en lo no-anticipable, en lo que viene intempestivamente, en la incondicionalidad, en la llegada del otro, en lo por venir. La democracia por venir sería la aperturabilidad de esas clausuras que buscan someter y controlar a lo monstruoso y catastrófico.

En el presente trabajo, se abordará la cuestión de lo catastrófico y lo monstruoso, vinculándolos con lo político, para identificar su efecto y funcionamiento al interior del "concepto" de democracia en Derrida. Desde la lectura que se propone, ambos "conceptos" guardan afinidad con la democracia por venir y posibilitan una apertura para pensar lo que se intenta alejar como extraño, distinto, maligno, catastrófico y monstruoso. En la obra derridiana lo catastrófico y monstruoso es teorizado en las primeras publicaciones, a lo que se abocará este escrito, y luego aparecerá en los Seminarios La bestia y el soberano I y II (DERRIDA, 2010; 2011) pasando por algunas otras obras como Márgenes de la filosofía ([1972] 1994) y La tarjeta postal ([1980] 2001) pero la vinculación con la Democracia por venir, como se propone realizar en este artículo, la realiza en los mencionados seminarios, pero no en las obras anteriores, por lo que se buscará señalar que la vinculación de lo catastrófico, monstruoso y la democracia data de esas primeras obras, aunque no sea de una forma explícita.

\section{El monstruo saussureano y lo catastrófico rousseauniano}

En De la gramatología, Derrida sostiene que el concepto de catástrofe atraviesa una gran parte de los postulados de Saussure y, en especial, de Rousseau. Pero más allá del rastreo del concepto en sí, resulta interesante la pregunta por lo catastrófico en general, la insistencia con que la retoma y deconstruye, 
asignándole un sitio privilegiado a la hora de leer el Ensayo sobre el origen de las lenguas y extendiéndola más allá de los límites económicos del texto.

La catástrofe va unida al surgimiento de la sociedad, la escritura y lo suplementario, no se la puede apartar de su origen violento y accidental. Lo catastrófico vendría a romper con la naturaleza, pero desde el interior de la misma, naturalmente, eso justamente es lo que lo vuelve un acontecimiento catastrófico. Lo que Saussure llama monstruoso, Rousseau lo asimila a lo catastrófico (DERRIDA, 2003, p. 54). Derrida se pregunta: ¿por qué Saussure reserva lo monstruoso a la escritura, por qué se centra en ella?, ¿por qué la escritura es dañina para la lengua? La insistencia en la gravedad de las "deformaciones" de la escritura estaría dada por la búsqueda de Saussure de liberar la lengua, alejándola de las acciones monstruosas, preservándola en su pureza. Lo monstruoso amenaza en el interior mismo de la lengua que con tanto ahínco busca proteger, surge ahí adentro eso tan temido. Pero lo monstruoso sería lo más natural en esa destrucción de la naturaleza, lo más interior en esa exterioridad. Lo monstruoso estaría en el interior de esa naturaleza pura de la lengua. Derrida se detiene en el tratamiento de lo monstruoso en Saussure, cuando éste sólo utiliza esa palabra una vez a lo largo de todo el Curso, pero sin nombrarlo, lo monstruoso de la escritura está presente en las reflexiones del lingüista ginebrino. ${ }^{1}$

1 Lacoue-Labarthe, analizando la música y su relación con el lenguaje, sostiene sobre la consideración que se tiene sobre la monstruosidad de la retórica, en una línea cercana a lo que realiza Derrida. "La rhétorique est donc une monstruosité. Le langage s'engendre contre nature: Apollon y est antérieur, le «fils» vient avant le «père». C'est plus qu'un «renversement». C'est une aberration, - ou l'impossible même [...]" (LACOUE-LABARTHE, 1979, p. 63). "La retórica es entonces
Derrida refiriéndose a la juntura entre el habla y el canto en Rousseau, sostiene que el intervalo que se produce es necesario y sólo es posible si se produce desde el interior y no sería lo accesorio al canto, porque sin él no se produciría el canto. Pero Rousseau, quería colocar al espaciamiento en un afuera ajeno a la nobleza del habla y el canto, quería que el espaciamiento le sobreviniera posteriormente y trajera aparejado la enfermedad y la muerte, produciéndose el acontecimiento catastrófico que produce el caos. Rousseau omite deliberadamente que ese acontecimiento se encuentra desde el inicio, es más, sin ese acontecimiento no habría ese comienzo, pero eso no es posible a sus ojos y por eso, tiene que ser la catástrofe que le sobreviene del exterior al canto y al habla plena. De la regulación (el espaciamiento lo asimila a la razón) a partir de la razón se producen esas catástrofes que quitan la espontaneidad y pasión al canto (DERRIDA, 2003, pp. 254-255). La filosofía se inmiscuyó en el ámbito de la poesía y el canto, dando por resultado el espaciamiento y el alejamiento de la sensibilidad.

A esta catástrofe, que Derrida sostiene que se rige por la ley de la regresión geométrica, se le añade una catástrofe aún más catastrófica que será la sustitución de la libertad política por la servidumbre, la cual Rousseau describe en la decadencia inevitable de Grecia que culminará en el Imperio Romano, que sólo acentuará y acrecentará esa degeneración del habla que dará lugar a la pérdida de la libertad. El espaciamiento y la razón darán por resultado la pérdida de la pasión y la libertad. Cada progreso tendrá en sí mismo el germen de su acontecimiento catastrófico que lo llevará a producir efectos

una monstruosidad. El lenguaje se engendra contra natura: Apolo es anterior, el "hijo" viene antes que el "padre". Es más que una "inversión". Es una aberración, - o incluso lo imposible [...]" 
compensatorios, los cuales producirán a su vez nuevos progresos y otros efectos catastróficos al infinito.

Derrida refiriéndose al estructuralismo, sostiene en el mismo sentido que se viene marcando:

[n]o hay, pues, nada paradójico en que la consciencia estructuralista sea consciencia catastrófica, a la vez destruida y destructora, desestructuradora, como lo es toda consciencia o al menos el momento decadente, período propio de todo movimiento de la consciencia (DERRIDA, 1987, p. 13).

Momento de toma de consciencia para el progreso, que quiebra y es quebrada. La catástrofe es la que da inicio a la palabra y a la sociedad civil, lo que Rousseau ve como un acontecimiento negativo que ocurre accidentalmente, Derrida demuestra que sin ese inicio catastrófico no habría cambio, se continuaría en un estado pre-civil, en la barbarie. El acontecimiento catastrófico sería absolutamente necesario para que los traspasos de un estado a otro se produzcan.

El espaciamiento se halla desde el origen, desde el interior mismo y no desde un afuera como pretendía fácilmente Rousseau, es desde el exterior del interior que se produce el espaciamiento que posibilita el canto y el habla. Ocurre de forma similar con la libertad política, que no se puede desvincular de la servidumbre, porque ambas están en el inicio, no existiendo una libertad pura desvinculada de toda servidumbre. Toda libertad en un sistema político implica una responsabilidad y en ese sentido, una cierta servidumbre donde debe someterse a determinadas normas. Servidumbre y libertad poseen un origen común.

Derrida deconstruye los postulados de Saussure y Rousseau y demuestra la complejidad al interior de los textos: la pretendida pureza que se quiere atribuir al habla no es tal, lo catastrófico se halla al interior, no pudiendo eludirse.

Derrida analiza los textos de Rousseau, en especial el Emilio (DERRIDA, 2003, pp. 257-260), y observa que existe una división y categorización con respecto a la imitación, una buena y otra mala. La buena imitación es aquella a la que se recurre para enseñarle al niño lo que debe realizar; pero la mala, es la que hace que permanezca en el signo como tal; es decir, queda embelesada por la imitación misma, sin trascender el acto mismo de imitar. Por lo tanto, la imitación posee esas dos caras en la propuesta rousseauniana: se recurre a ella, pero al mismo tiempo se la rechaza.

La mala imitación, según Rousseau, es una desviación de la imitación, una anomalía monstruosa. La imitación no es mala en sí, sino que su maldad proviene de esa desviación, que conduce a permanecer en la imitación, siendo una imitación de la imitación. Habría que saber hasta qué punto se la utiliza adecuadamente y dónde se inicia la perversión de recurrir meramente al signo, por el signo mismo. Lo monstruoso es recurrir a la imitación y permanecer en el signo, deviniendo en una perversión. Esta lógica que postula Rousseau, se le viene en encima, ya que se recurre a la imitación desde el inicio para luego desestimarla y considerarla perniciosa.

Para Rousseau la mala imitación, producto del vicio, da origen a lo social (DERRIDA, 2003). En sociedad, no se imita para mejorar, sino que se lo hace solamente como una forma de engaño hacia los demás. Los animales imitan a los que consideran que son mejores, pero los hombres imitan deformando ese fin que hay en la naturaleza. Por eso, la imitación en sociedad se transforma en simulación e intento de engaño, por ello es monstruosa. En algunas cuestiones socia- 
les y política se puede apreciar lo que sostiene Rousseau sobre la imitación, ya que se busca imitar una actitud para obtener algún beneficio sin que importe el mejoramiento de la situación. Este rechazo a la imitación es el realizado por Platón con respecto a los poetas, porque se basan en la imitación y sólo tienen lugar en un "Estado enfermo", ya que un Estado sano no los necesitaría (PLATÓN, 1871, p. 56; 1986, pp. 128/162. Se podría tomar todo el Libro X de la República, en especial: 457/463-466/477).

Lo catastrófico no es malo en sí para el sistema que propone Rousseau, ya que eso le permite introducir el progreso, sin él no se produciría el quiebre y el paso a una nueva "etapa".

Pero Rousseau se empeña en exaltar su negatividad y excluirlo de su sistema, atribuyendo que todo acontecimiento catastrófico es siempre natural. Es decir, es natural y al mismo tiempo rompe con la naturaleza a la que pertenece, se encuentra en ese traspaso donde se transforman las leyes de la naturaleza, perteneciendo a ella y a la vez, quebrantándolas (DERRIDA, 1972, p. 172). La catástrofe es no-racional, ni dentro ni fuera de la naturaleza, azarosa, imprevisible e introduce la suplementaridad que no es concebible por la razón. Lo catastrófico no se puede comprender al interior de una lógica que lo preceda, ya que es él quien da origen a una nueva lógica. El lenguaje y la sociedad son consecuencia de lo catastrófico, del azar, del accidente, del suplemento que se mueven por fuera de la razón. La catástrofe aparece de forma arbitraria y Rousseau, la contrapone a lo natural, marcando lo incontrolable y negativo que trae aparejado lo catastrófico al ser producto de una arbitrariedad. Contraposición dicotómica entre lo natural y arbitrario tan presente en los textos de Rousseau
(DERRIDA, 1972, p. 173). Lacoue-Labarthe, refiriéndose a Hölderlin y la tragedia griega, sostiene que lo monstruoso es el acoplamiento del dios y del hombre “...ese ilimitado devenir-uno y esa transgresión (hybris) del límite..." (LACOUE-LABARTHE, 2010, p. 90), que la tragedia tendría la función introducir pureza. Es interesante la observación de Lacoue-Labarthe sobre Hölderlin, ya que marca que lo monstruoso es la incrustación de dios y el hombre, de uno en otro, ese quebrar el límite que existe entre uno y otro, mezclar todo, que no se pueda diferenciar, salir de la tranquila clasificación. Y en ese mismo texto, analizando la Psicología de las masas de Freud, sostiene que lo monstruoso es la encarnación del bien y el mal en el héroe, de allí la tragedia del mismo, ya que tiene que ser temido y a la vez, amado (p. 238). No ser ni uno ni otro o ser los dos a la vez, no se sabe qué es. Lo monstruoso se hallaría en ese camino intermedio entre un dios y un hombre, entre ser pura bondad o pura maldad. Estaría en la indeterminación, en ese hiato donde no se tiene certeza.)

Pero las sociedades, si bien nacidas de la catástrofe, se construyen para salvar los accidentes de la naturaleza, son un mal necesario que pone freno a la fuerza descontrolada de la naturaleza. Al mismo tiempo, la catástrofe se regula a sí misma, para que lo catastrófico de ella, no se vuelva en contra y se autodestruya. En la catástrofe se encuentra funcionando una economía (Sobre el tema de la economía en Derrida ver: BISET, 2012, pp. 123-153), que al presentarse para producir el quiebre y progreso, se autolimita para no autodestruirse.

Antes de la catástrofe los hombres se encuentran dispersos y cuando aparece los reúne, pero al volverse persistente los vuelve a disgregar. Es entonces con la aparición de la 
catástrofe que los hombres, al reunirse, necesitan hablar, necesitan suplir. Para Rousseau en el Norte, el calor natural del sol en verano y primavera es suplido por el fuego en otoño e invierno, a su alrededor se congregan para calentarse y compartir, allí es donde surge el sentimiento de humanidad. Nace en torno a un suplemento, a una catástrofe de la naturaleza porque es eliminada la "primavera perpetua” (DERRIDA, 1972, pp. 175-177). Pasando de la necesidad a la pasión. En el Sur, en cambio, lo que congrega es el agua ya que no todas las regiones poseen agua en la misma proporción. Se produce el camino inverso, que va de la pasión a la necesidad, por esto Rousseau otorga preeminencia a los lugares donde reinan los climas cálidos, porque allí es donde nace la humanidad. La calidez de determinadas regiones se acerca más a la "primavera perpetua", está más cerca de la pasión y alejada de la necesidad. La lengua y la sociedad que surgieron de esas regiones, son absolutamente puras, no existe el suplemento, la lengua estaba cercana al canto y no articulada ni acentuada. En esas condiciones surge la sociedad sin degradación, cercana a la pureza. Esa sociedad no se origina de un contrato, leyes ni representantes, sino que es una "fiesta" donde no se tiene noción del tiempo, sino que todo es pura presencia (DERRIDA, 2003, p. 328). No es la sociedad constituida, es el camino que lleva a salir del estado de naturaleza y entrar en sociedad, es ese el momento siempre presente de la "fiesta", es la presencia siendo siempre presente, un paso por el cual no se debería acabar de pasar jamás.

En ese paso, el deseo y el placer se confunden, es puro sentir. Luego de la fiesta se percibe la discontinuidad entre el tiempo de la presencia siempre presente de la fiesta y lo posterior a ella. La sociedad es la que se constituye luego de la fiesta, allí se per- cibe la discontinuidad de la presencia pura y siempre presente de la fiesta. Después de ella, aparece el suplemento, la articulación, la prohibición del incesto, en definitiva, la catástrofe. En sociedad se produce la prohibición del incesto, pero antes de la fiesta había familias, pero no generaciones, no había amor ni pasión, sino que reinaba el instinto y la necesidad. Pero la culminación de la fiesta, da inicio a la prohibición del incesto como lo postulara Freud en 1913 (FREUD, 1986).

La suplementaridad abre a la catástrofe que quiebra y aleja, pero al mismo tiempo es el instante más próximo a ella; un alejamiento que aproxima. Es a partir de ese suplemento que se puede suplir perfectamente, porque se lo hace luego de la catástrofe. Pero el suplemento como el representante, intenta ocupar un lugar que no es suyo, estar en representación de otro y que ese otro le otorgue un poder para que lo represente sin representarlo plenamente. No se representaría, no se supliría si se estuviese en presencia de lo que buscan representar. Por ello Rousseau, no está de acuerdo con la representación, porque se tiende a olvidar lo que se representa en el acto de representación.

La naturaleza, ante esa primera catástrofe, se degrada y sólo se la suple deficientemente; por ello, cuando se retorna a un estado de naturaleza es siempre de forma defectuosa porque no es la primera naturaleza, sino que es suplemento que busca ocupar un lugar, haciéndolo de forma desastrosa. La naturaleza representada, vuelve en sus representaciones, pero nunca de la manera en que se dio prístinamente. De allí, el "juego" infinito de recurrir a la representación porque subsiste algo de lo representado y a su vez, se borra eso que tanto se anhela representar. Eso es lo que Rousseau desdeña 
del suplemento, eso es lo catastrófico. Allí, es donde Derrida observa que si la naturaleza no está plenamente presente en ninguna representación, es que se da una representación de representación, un suplemento de suplemento.

El suplemento viene a cubrir el espacio de una naturaleza deficiente y que no podrá volver, porque su retorno sería pernicioso, por eso recurre al suplemento, para evitar la mala naturaleza. El análisis de Derrida, del texto de Rousseau, ahonda en esa tensión que lleva al retorno a la naturaleza y a despreciar al suplemento, por un lado; pero por otro, la irreprimible tentación y necesidad de recurrir a él, para ocultar las carencias de una naturaleza que desde el inicio necesitó del suplemento. Acercamiento al suplemento para estar próximo a la naturaleza, alejamiento de la naturaleza para no caer en la mala naturaleza. Y el suplemento siempre, inevitablemente, cerca.

Para Derrida, Rousseau piensa el origen de una nueva estructura en base al "modelo de la catástrofe", es decir, que la catástrofe se da en la naturaleza, de forma natural, se produce una separación de una naturaleza con respecto a otra (DERRIDA, 1987, p. 400).

El suplemento, como la escritura, es un mal, una política de sojuzgamiento que aleja de la pasión, que se torna menos viva y elocuente, que no habla al pueblo. El recurso a la escritura es un abuso político, para distanciar y crear dispersión. Lo catastrófico es que en las capitales modernas se tiende a ese uso que Rousseau considera deplorable. Ese suplemento se colocaría en el sitio de lo que busca suplir, pero no lo logra, no lo representa. La representación, como se veía, debería representar plenamente lo que representa, es decir, que el representado esté en el lugar del representante, pero como esto no se da, se tiene que recurrir al representante, pero éste no debe ocupar un lugar en el cual deje de lado al representado y considere que sólo él decide. Gran problema este en los sistemas de gobiernos representativos que Rousseau observa con certeza, pero más allá de ello, Derrida analiza que la lectura de Rousseau sobre una presencia absoluta y de plena voz, no es posible de realizarla porque desde el origen ya estaba el suplemento con su capacidad de iteración. Esa añoranza rousseauniana sería "ingenua" y limitada desde la lectura derridiana. Es así, que desde la construcción de Rousseau se requiere de lo catastrófico para que rompa e invierta el curso "normal" de las cosas y retornar al "origen". Es así que le otorga una centralidad a lo catastrófico y suplementario, cuando en realidad quisiera mantenerlos relegados.

La búsqueda de Rousseau por dejar en lo exterior a lo catastrófico, al suplemento, es infructuosa, ya que recurre una y otra vez a aquello que quiere eludir. El suplemento se halla en el interior, desde el "origen" y no es un añadido posterior, por ello se encuentra siempre intentando alcanzar lo no-suplementario basándose en suplementos (BENNINGTON, 1993, pp. 16/38). Y el suplemento no se inscribe en la lógica dicotómica de la metafísica de la presencia, está a medio camino entre lo que suple y por lo que es suplido, entre lo que representa y el representante. Husserl, desde la lectura de Derrida, realiza el mismo gesto de intentar dejar en el exterior a la catástrofe, como lo dañino que adviene e irrumpe en un estado de armonía. Abordando el tema de la idealidad y la facticidad en la Introducción al Origen de la Geometría, Derrida sostiene que las “idealidades culturales "encadenadas'”' serían afectadas por una catástrofe o destrucción fáctica, pero no así la "idealidad plenamente 
liberada y la objetividad absoluta del sentido" que permanecerían intactas a los efectos externos:

Al no depender la verdad esencialmente de ninguno de ellos, podrían ser todos destruidos sin que la idealidad absoluta, en su sentido mismo, fuera afectada. Sin duda, sería modificada, mutilada, trastornada de hecho, tal vez desaparecería de hecho de la superficie del mundo, pero su sentido-de-ser de verdad, que no se halla en el mundo -ni en este mundo ni en otro-, en sí mismo permanecería intacto. Conservaría su propia historicidad intrínseca, sus propios encadenamientos, y la catástrofe de la historia mundana seguiría siéndole exterior (DERRIDA, 2000, p. 93).

La catástrofe pertenece a la exterioridad, permanece allí afuera, sin afectar a la idealidad, al interior. Como Rousseau, considera que lo catastrófico no puede ser engendrado desde el interior, la idealidad sólo es relativamente afectada porque no depende, no tiene un contacto directo con lo exterior. "La hipótesis de la catástrofe mundial podría incluso servir en este sentido de ficción reveladora" (DERRIDA, 2000, p. 94 y p. 96). La catástrofe solamente tiene el valor del ejemplo, conmueve, pero no perturba a la idealidad en el interior.) Esta idea es fundamental comprenderla, en especial para un sistema democrático, ya que los representantes no deben arrogarse el poder de tomar decisiones sin tener en cuenta a los representados y que jamás podrán representarlos plenamente.

Es lo catastrófico lo que mantiene en funcionamiento desde interior a toda la construcción rousseauniana, aunque él procure, con no pocos esfuerzos, colocarlo externamente y perjudicial al progreso. Sin lo catastrófico el progreso no sería posible, es la catástrofe misma que mueve y hace progresar.

\section{Lo monstruoso derridiano}

Como se sostuvo líneas arriba, lo monstruoso en Saussure se podría entender como lo que Rousseau llama lo catastrófico, pero para Derrida, lo monstruoso no sería lo que viene simplemente a conmover las bases sin llevar al extremo de retornar a un estado de naturaleza, pero sí lo suficientemente fuerte para hacer progresos que no serían posible sin un acontecimiento catastrófico; sino que sería lo por venir, lo que rompe de forma absoluta con todo lo instaurado, lo monstruoso es el peligro absoluto. "Rompe absolutamente con la normalidad constituida y, por lo tanto, no puede anunciarse, presentarse, sino bajo el aspecto de la monstruosidad" (DERRIDA, 2003, p. 10). Es un quebrantamiento de los sustentos, que se tornan ineptos para comprender o permitir una lectura de eso que está por venir, por ello es considerado monstruoso y solamente un alejamiento de la lógica del sistema y un acercamiento a un pensamiento sobre lo monstruoso permitiría estar más próximos a la cuestión. ${ }^{2}$ Para Canguilhem, lo monstruoso es lo que quiebra el horizonte de seguridad que se poseía, no pudiendo retornar jamás a aquel: "[...] el monstruo sería solamente lo otro, un orden distinto al orden más probable" (CANGUILHEM, 1962, p. 33). Lo absolutamente otro, de lo que no se posee ni un solo indicio para pensarlo, para saber: ¿qué es? Lo monstruoso abre una grieta en donde todo es orden, donde no hay cabida para ello, donde todo es posible y es posible que

2 Derrida en Papel Máquina, refiriéndose al libro por venir, sostiene que al no tener una existencia, al no poder asirlo, ni siquiera anticiparlo o tener alguna mínima referencia de lo que es o podría ser, se lo asocia con lo monstruoso. No sigue ningún modelo, ni norma, no reproduce lo que lo precede, "es" un acontecimiento monstruoso, que se presenta sin anuncio, intempestivamente, monstruosamente (DERRIDA, 2003a, p. 29). 
se lo siga considerando por siempre monstruoso, al realizar una y otra vez la apertura a lo por venir, rompiendo con lo constituido. Aquí, se observa la cercanía entre lo que sostiene Derrida y Canguilhem sobre lo monstruoso.

Derrida sostiene que lo monstruoso irrumpe como un nacimiento de lo innombrable, de lo que no se subsume bajo ninguna especie, bajo ninguna clasificación, lo desconocido más allá de su nominación como desconocido (DERRIDA, 1987, p. 401). Lo monstruoso genera temor porque se sustrae a todo poder, se pierde poder ante la pérdida de referencia, ante lo que no se sabe que va a venir.

"Une des significations du monstrueux, c'est qu'il nous laisse sans pouvoir, qu'il est justement trop puissant ou en tout cas menaçant pour le pouvoir" (DERRIDA, 1992, p. 399). ${ }^{3}$ El poder de lo monstruoso radica en que atemoriza y rompe con lo establecido quebrantando el orden e introduciendo incertidumbre. Pero al mismo tiempo, lo monstruoso marca un punto en el cual permite ser consciente de la norma, de la regla, sin lo monstruoso quizás no se sería consciente de lo normal. "À ce moment-là la monstruosité peut révéler ou faire prendre conscience de ce qu'est la normalité; devant un monstre on prend conscience de ce qu'est la norme et quand cette norme a une histoire [...]" (DERRIDA, 1992, p. 399). ${ }^{4}$ Lo monstruoso permite ver o ser consciente con respecto a lo cual se lo considera monstruoso, es decir los parámetros que fijan lo normal y anormal, pero él no se puede en-

3 "Una de los significados de lo monstruoso, es que nos deja sin poder, es justamente demasiado poderoso o al menos, amenazante para el poder."

4 "En ese momento la monstruosidad puede revelar o hacer tomar conciencia de qué es la normalidad; delante un monstruo se toma conciencia de qué es la norma y cuando esa norma tiene una historia." casillar en ninguno de los dos, rompe con ese binarismo. Pero una vez que se identifica a lo monstruoso como tal, se inicia ya un proceso de domesticación para encasillar, clasificar, coaptar, etc., para que no genere un efecto desestabilizador y atemorizante. Se buscará por todos los medios normalizar a lo monstruoso, para que pierda su monstruosidad, para que se acostumbren a él, pero nuevamente aparecerá otro monstruo incomodando y el proceso empezará una vez más, hasta el infinito. El acontecimiento monstruoso se reeditará por siempre y es allí donde está la riqueza de lo que está más allá de lo inclasificable mismo. ${ }^{5}$

La democracia por venir posee los rasgos de la monstruosidad que atemoriza, que no se puede anticipar e irrumpe sin poder ser clasificada; pero al mismo tiempo, marca la consciencia de la norma, marca la relación entre el derecho y la justicia, entre lo condicional e incondicional.

Lo monstruoso produce repulsión por el temor que se le tiene, pero a su vez provoca

5 Sería interesante comparar lo ominoso freudiano con lo monstruoso derridiano, para extraer las cercanías que existen en ambas propuestas, aunque con diferencias notorias. Pero eso será un trabajo para otra ocasión, aquí simplemente remitimos a unas citas de Freud. "Si la teoría psicoanalítica acierta cuando asevera que todo afecto de una moción de sentimientos, de cualquier clase que sea, se trasmuda en angustia por obra de la represión, entre los casos de lo que provoca angustia existirá por fuerza un grupo en que pueda demostrarse que eso angustioso es algo reprimido que retorna. Esta variedad de lo que provoca angustia sería justamente lo ominoso, resultando indiferente que en su origen fuera a su vez algo angustioso o tuviese como portador algún otro afecto. La segunda: Si esta es de hecho la naturaleza secreta de lo ominoso, comprendemos que los usos de la lengua hagan pasar lo «Heimliche» $\{$ lo «familiar»\} a su opuesto, lo «Unheimliche» (págs. 224-6), pues esto ominoso no es efectivamente algo nuevo o ajeno, sino algo familiar de antiguo a la vida anímica, sólo enajenado de ella por el proceso de la represión" (FREUD, 1986, pp. 240-241). 
atracción porque escapa a la norma y regla. Se podría marcar, salvando las distancias, una relación con lo que Benjamin sostiene sobre el "gran delincuente", que atrae y a la vez es temido. Pero atrae porque al desafiar la ley deja al desnudo la violencia del sistema (jurídico) que oprime (BENJAMIN, 1967, p. 27. También ver DERRIDA, 2008, p. 87). Así, se puede establecer que lo monstruoso al producir el quiebre, deja en evidencia la violencia de los encasillamientos a los que se recurre sistemáticamente, para obtener poder de ese orden impuesto. Asimismo, la monstruosidad también es aplicada, a lo largo de la historia de la filosofía, al poder del Estado, el caso más renombrado es el de Thomas Hobbes con su Leviathan. Derrida lo analiza en el Seminario La bestia y el soberano (DERRIDA, 2010), donde el Estado soberano puede ser encarnado por una "bestialidad monstruosa" (DERRIDA, 2010, p. 47), pero es creada por el hombre, ya que toma la figura de lo monstruoso para colocar al Estado soberano en un sitio que no pueda ser alcanzado y sometido, concediéndole un poder casi ilimitado, pero al buscar una cierta funcionalidad o rol a la monstruosidad se busca domeñarla y tener un control sobre ella, lo que derivaría en una monstruosidad no monstruosa. "[...][M]onstruo estatal creado y dominado por el arte del hombre, monstruo animal artificial que no es sino el hombre artificial [...]" (DERRIDA, 2010, p. 49). Una monstruosidad artificial, que pretendería ser monstruosa para generar temor, pero sin conseguir ser lo suficientemente monstruosa. Es un producto del hombre, calculado por él, sin romper con lo establecido como haría lo "verdaderamente" monstruoso.

La democracia por venir sería ajena a esa monstruosidad calculada. En ese mismo seminario, Derrida se refiere a lo mons- truoso desde un principio ético o de justicia que es la responsabilidad hacia lo otro, con lo "monstruosamente otro", lo que cae en el ámbito de lo incognoscible, es ahí donde se podría empezar a hablar de justicia y hospitalidad (DERRIDA, 2010, p. 139). Es a partir de la apertura a lo "monstruosamente otro" que se puede iniciar un pensamiento hacia una democracia más allá del cálculo, la condición y la soberanía.

\section{La autoinmunidad de la monstruosidad}

Retomando la postura de Saussure, lo monstruoso sería la escritura porque es esa prótesis que aparece generando temor, que no se la puede controlar, que traería con ella el mal, que quitaría la pureza al habla, pero lo monstruoso no es exterior y no se puede desligar jamás de él, aunque siempre se ignore lo que es. Derrida coloca a lo monstruoso más allá de la concepción que de él posee Saussure, porque éste trata de identificar al monstruo de la escritura, cuando no se puede tener una certeza sobre lo que lo monstruoso es. Lo monstruoso escapa a toda clasificatoria dicotómica, no es ni esto ni lo otro, no es lo contrario a aquello, "es" lo que no se sabe "qué es". Se escabulle ante la pregunta por la esencia, pero al mismo tiempo a la pregunta por lo sin-esencia. Asimismo, es oportuna la reflexión que realiza Lacoue-Labarthe, refiriéndose al nazismo, que lo monstruoso no debe ser utilizado para ocultar y eludir el pensamiento y tratamiento de ciertas cuestiones por ser consideradas monstruosas, sino que se debe acercar cada vez más para "comprender", para poder abordar temas difíciles (LACOUE-LABARTHE, 2002, p. 146).

El monstruo es un viviente, que no se sabe lo que es, pero ese que no es algo defi- 
nido, es algo con vida. En ese sentido se podría arriesgar que utiliza los mecanismos de los seres vivientes de la auto-inmunidad, sacrificando ciertas partes para poder subsistir, para mantenerse con vida. Por ello, para continuar siendo con sus características de inclasificable, no-identificable, indeterminable, etc., resigna partes para no sucumbir a esa búsqueda constante por reducirlo a algo conocido, dominable, predecible y no temido. Resistencia que demanda distintas estrategias, nuevas formas de ocultamiento, rapidez y fluidez para no ser detectado, pero en eso se extravía algo de la monstruosidad que logra que algunas cosas, acciones o personas sean llamadas, aunque de forma deficiente, monstruosas. Algo en esas denominaciones hace que se pierda la "verdadera" monstruosidad, hace que cada vez sea menos monstruosa o más conocida. Se podría asociar ese proceso a lo autoinmunitario que destruye sus propias protecciones para inmunizarse contra su propia inmunidad. Donde se pierde algo de sí, para mantenerse:

[...] las dimensiones de la suplementariedad autoinmunitaria y autosacrificial, esa pulsión de muerte que se afana en silencio sobre toda comunidad, toda auto-co-inmunidad y, en verdad, la constituye como tal, en su iterabilidad, su herencia, su tradición espectral. Comunidad como auto-inmunidad co-mún: no hay comunidad que no alimente su propia autoinmunidad, un principio de autodestrucción sacrificial que arruina el principio de protección de sí (del mantenimiento de la integridad intacta de uno mismo), y ello con vistas a alguna super-vivencia invisible y espectral. Esta atestación autocontestataria mantiene a la comunidad autoinmune en vida, es decir, abierta a otra cosa distinta y que es más que ella misma: lo otro, el porvenir, la muerte, la libertad, la venida o el amor del otro, el espacio y el tiempo de una mesianicidad espectralizante más allá de cualquier mesianismo (DERRIDA, 2003b, pp. 105-106).

En esa autoinmunidad que resigna algo para conservarse, que no puede deshacerse de esa autodestrucción, nunca lo monstruoso podrá ser dejado de lado, habita en la interioridad.

Todo proceso que busque eliminar lo monstruoso lo hace a través de la monstruosidad: atacando a esa monstruosidad para derrotarla; lo que puede derivar en dos consecuencias igualmente riesgosas: a) un exceso de monstruosidad para atacar a lo monstruoso, puede que se torne más monstruoso que lo monstruoso que se quiere evitar; b) un ataque de lo monstruoso sin que esté a la medida de lo monstruoso que se combate, podría dar por resultado que lo monstruoso que se quiere combatir termine prevaleciendo. Es por medio de este proceso autodestructivo, en ese riesgo siempre presente, que se realiza la apertura a lo por venir de la democracia y al mismo tiempo a la infinita vulnerabilidad de convivir con lo catastrófico, monstruoso y terrorífico. ${ }^{6} \mathrm{De}-$ rrida (2004) prosigue:

[...] todos estos esfuerzos por atenuar o neutralizar el efecto del traumatismo (para negarlo, reprimirlo, olvidarlo, para hacer su duelo, etc.), son, a su vez, tentativas desesperadas. Y movimientos autoinmunes que producen, inventan y alimentan la monstruosidad que pretenden abatir.

Lo que jamás se dejará olvidar es entonces el efecto perverso de la autoinmunidad misma. Hoy sabemos que la represión, en el sentido

6 "[...] la fuente más irreductible del terror absoluto, la que, por definición, se encuentra más desarmada frente a la peor amenaza, sería la que procede "desde adentro", de esa zona en donde el peor "afuera" vive "en mí". En ese caso, mi vulnerabilidad, por definición y por estructura, por situación, no tiene límites. Y de ahí el terror. El terror siempre es, o se convierte en, "interior", al menos en parte" (DERRIDA, 2004, p. 261). 
psicoanalítico y en el sentido político-policivo, político-militar, político-económico, produce, reproduce, regenera precisamente aquello que trata de desactivar (pp. 148149).

Esa economía de fuerzas en la lucha para no terminar engendrando lo que se está combatiendo. La autoinmunidad podría acarrear una monstruosidad mayor a la que intenta eliminar.

Lo monstruoso desde la mirada de Derrida es el intento por dejar de lado lo que no es controlable, lo que escapa al poder de algunos y es por ello, que todo lo que no sea factible de sometimiento es temido y nominado como peligroso, como un monstruo, para que nadie se acerque a él, para que huyan de él. Lo monstruoso en ese sentido, sería una estrategia netamente política que anhela mantener todo bajo control y, por lo tanto, lo que no se adecua a ese control cae en la monstruosidad. Lo monstruoso sería un modo de mantener una política que busca permanecer sin cambios, sin advenimiento de nada que atente contra su comodidad, una política que no se piense, que solamente se reproduzca ciegamente, una política que clausura lo por venir, que se mantiene en un horizonte donde todo es previsible, donde no podrá introducirse mejoras, ni tampoco críticas a la misma. Lo por venir es lo monstruoso, es hacia lo que la deconstrucción conduce.

Este ocultamiento y rechazo de todo lo que vaya en contra de lo que se sostiene, genera gastos de fuerzas, tensión y se lo realiza no sin el recurso a la violencia, por eso la aparición de la escritura sería violenta para ellos, pero su estrategia sería aplicar más violencia para ocultar a la monstruosa y violenta escritura que sólo trae catástrofe.

Se podría relacionar lo político con el tratamiento que realiza Derrida de lo catastró- fico y la cercanía con la metáfora. Marca el descentramiento de la posición sobre la forma de comprender la metáfora, centrándose en una metáfora que se centra en el móvil, en el transporte y no en lo transportado, en lo que conduce al tema y no el tema en sí. Derrida (1989) lo expresa de la siguiente manera:

[...] si se pretendiese que retirada-de se entendiera como una metáfora, se trataría de una metáfora curiosa, trastornadora, se diría casi catastrófica, catastrópica: tendría como objetivo enunciar algo nuevo, todavía inaudito, acerca del vehículo y no acerca del aparente tema del tropo [...] Tal catástrofe invierte, pues, el trayecto metafórico en el momento en que la metaforicidad, que ha llegado a hacerse desbordante, no se deja ya contener en su concepto llamado "metafísico"”' (p. 60).

Derrida recurre al neologismo "catastrópica” (DERRIDA, 2001, p. 146) para referirse a la metáfora, que se centra en la vía y no en el tema. Así, tomando la frase de Heidegger, la "casa del ser" sostiene que no es la "casa" lo que acerca al entendimiento de lo desconocido que sería el "ser", sino que es a la inversa que el adecuado pensamiento sobre el ser, permitiría pensar la casa. Pero tampoco sería una inversión simple, donde el ser diga más de la casa, que la casa del ser, sino que es un lugar de indeterminación, donde los términos supuestamente bien conocidos se tornan complejos y lleva a pensar en el desconocimiento de los mismos (DERRIDA, 1989, pp. 61-62). Es la “catástrofe metafórica" que desborda la metaforicidad habitual, para situarse entre lo metafórico y literal, en la quasi-metáfora. La retirada de la metáfora haría pensar en ella, en sus límites, en la literalidad y metaforicidad. ${ }^{7}$

7 Derrida se detiene en el mismo punto, cuando analiza lo postal centrándose en lo destinal (DERRIDA, 2001, pp. 68-71). 
En el "trastocamiento y en las relaciones invertidas" (DERRIDA, 2001, p. 30) es donde surge lo catastrófico, eso que rompe con el orden, que "introduce" el caos. Es lo que deja ver el caos que subyace a todo orden, a toda regla o norma, etc.:

[...] este caos e inestabilidad, que es fundamental, fundador e irreductible, es al mismo tiempo naturalmente lo peor que debemos enfrentar con las leyes, reglas, convenciones, política y hegemonías provisionales, pero al mismo tiempo es una suerte, una posibilidad de cambiar, de desestabilizar (DERRIDA, 1998, p. 163).

Es la apertura de lo catastrófico, el paso más allá, pensando en qué es una catástrofe, en que no se puede comprender, dominar, distinguir claramente. Lo figurado y lo propio ya no encuentran límites fijos y claramente demarcados, no son lo mismo, no se confunden, pero ya no se tiene la certeza ciega de su distinción.

Si se traslada al campo político, lo catastrófico que produciría la metáfora es el pensamiento sobre lo no pensado, lo no tenido en cuenta, la apertura a romper con esas estabilizaciones que alejan del caos. Las desestabilizaciones para nuevas estabilizaciones, y así continuamente. Se podría relacionar, salvando las distancias, con lo que sostiene Mouffe (2007):

[...] todo orden es político y está basado en alguna forma de exclusión [...] Todo orden hegemónico es susceptible de ser desafiado por prácticas contrahegemónicas, es decir, prácticas que van a intentar desarticular el orden existente para instaurar otra forma de hegemonía (p. 25).

En esta continua lucha por el establecimiento del "orden", o de una determinada forma de comprenderlo, se producen esos movimientos por intentar hacer prevalecer el punto de vista de cada cual. Lo catastrófi- co serían los que están por fuera, lo que se excluye; luego, al ser incluidos o prevaler su punto de vista, son los que quedarán al margen de esa nueva decisión los que deberán buscar ser incluidos, para excluir a otros y así sucesivamente.

Esa apertura de la catástrofe metafórica sería cambiar el centro de atención, más aún, no quedarse con lo que se debe prestar atención, no cerrarse a lo que se dice que es literal y metafórico. Exceder esos límites, para los que están por fuera puedan ser "incluidos", para no dejar afuera a cuestiones que solamente serían tratadas de manera metafórica. Centrarse en la vía y el vehículo como lo hace Derrida con la deconstrucción de la metáfora, es realizar un vaciamiento con relación a todo contenido que pudiera dar pautas para una exclusión, para perpetuarse en el poder y no atender a demandas de otros sectores. Permite un (des)centramiento y expansión que torna a la deconstrucción inherentemente política. Este posicionamiento permite plantear una democracia por venir que esté atenta a los excluidos. Por ello, la democracia por venir se sustenta en lo catastrófico y monstruoso.

Lo catastrófico y lo monstruoso se han buscado obliterar, silenciar y alejar de toda posibilidad de plasmación, siempre lo desconocido se planteó como lo que traería el mal y la destrucción, el cambio. Todo cambio es visto como una posibilidad catastrófica y representada a través de la monstruosidad. De allí, que la deconstrucción que realiza Derrida de dichos conceptos, lleva a una resignificación de los mismos, ya que lo que quieren eludir se halla en su interior, tornándose imposible su eliminación, sin la propia eliminación. Por ello, lo catastrófico y lo monstruoso se relacionarían con la democracia por venir, ya que toda búsqueda de imposición de una forma de gobierno y de un pensamiento polí- 
tico, tratarían por todos los medios de excluir cualquier forma de pensamiento que vaya en contra de lo que se quiere imponer. La aperturabilidad que posibilita la democracia por venir, pero al mismo tiempo, la marcación de los límites y la imposibilidad de ser plasmada absolutamente, están en relación con lo catastrófico, como rompimiento de lo establecido, y con lo monstruoso, como lucha autoinmunitaria contra sí misma, en uno de los sentidos, que tiene el poder de criticarlo todo, incluso a ella misma.

\section{La monstruosa democracia}

El tratamiento de lo catastrófico y monstruoso, que se acaba de proponer, permite una ampliación de los márgenes de la democracia y posibilita pensar los limites-ilimitados en los que la cuestión se desarrolla y se reconfigura a cada paso. La Democracia por venir estaría atenta a los espectros del pasado, siendo fiel a esa herencia; pero al mismo tiempo, abriría a lo por venir, a lo catastrófico y monstruoso:

La democracia es el único sistema, el único paradigma constitucional en el que, en principio, se tiene o se arroga uno el derecho a criticarlo todo públicamente, incluida la idea de democracia, su concepto, su historia y su nombre. Es por lo tanto el único universalizable, y de ahí derivan su oportunidad y su fragilidad. (Derrida, 2005, p. 111)

Aquí, se podría ver la apertura de la democracia y el riesgo que conlleva, incluso para ella misma. Pero Derrida busca salvar esa caída en una ausencia de democracia por medio de la justicia (2005, p. 116-117; 1994), es decir, que la justicia imposible de reducirse a lo estatal o al derecho siempre va ligada al por venir de la democracia, para que esa aperturabilidad de la democracia que rompe las consideraciones estereotipadas sobre lo monstruoso y catastrófico, como veíamos, tienda a otra democracia pero sin dejar de cuestionar constantemente los límites y eso es el trabajo permanente de "[...] una crítica política militante y sin fin. En tanto que arma arrojadiza contra los enemigos de la democracia [...]" (DERRIDA, 2005, p. 110).

Lo catastrófico al ser vinculado a lo maléfico, dañino, accidental y artificial, fue dejado al margen; pero todo lo que es considerado de esa manera, es porque es temido por no ser

conocido y controlado. Por ello, la escritura será considerada monstruosa y portadora de catástrofe, pero esto sólo será un movimiento político que busca instaurar la jerarquización.

Pero Derrida demuestra que eso mismo que es recelado habita en el interior de lo que se considera puro y alejado de lo monstruoso y catastrófico. La democracia por venir al estar

abierta al acontecimiento, a lo por venir, no ve como monstruoso a lo desconocido, a lo que no se puede controlar y a lo que cae por fuera de toda calculabilidad.

Aún más, la democracia por venir sería lo monstruoso, al no poder ser anticipada, al ser una venida sin horizonte de espera y una mesianicidad sin mesianismo.

Lo monstruoso y la democracia por venir, rompen de forma absoluta con lo instaurado, pero eso permite pensar la normalidad, la ley y el derecho, que se están quebrando, conduce a una crítica profunda de lo normado. Ambas van en contra de todo poder instituido, por eso son atemorizantes, más aún, terroríficas, para los que buscan persistir y perpetuarse en su lugar de poder.

La democracia por venir debe auto-inmunizarse para que se dé una economía de monstruosidad, ya que una forma "excesiva" de ir contra lo monstruoso que atenta con- 
tra ella, podría tornarla monstruosa para ella misma; pero, se debe estar a la altura de lo monstruoso que se lucha para que aquello no salga victorioso.

El movimiento al que incita la deconstrucción es al descentramiento de posiciones erigidas, para dirigir la atención a zonas dejadas a oscuras y obliteradas, lo que dará lugar a una situación de caos, catástrofe y monstruosa, porque traerá consigo lo por venir que será imprescindible para modificar y lograr novedosas perspectivas. Estos puntos extraídos a partir del análisis de lo catastrófico y monstruoso, y la importancia que poseen para el logofonocentrismo que se deconstruye, posibilitan posicionar a la democracia por venir como aquello que siempre se considerará un monstruo por tender a la apertura hacia lo desconocido, por ser hospitalaria con el(lo) otro, por mostrarse siempre movediza, siempre por venir. Pero no es pura apertura a lo que "vendrá", sino que se debe dar una memoria por los que ya no están, que asedian constantemente, un duelo interminable por los desparecidos, por los olvidados, por los que no tuvieron posibilidad de duelo.

Luego del recorrido propuesto, se puede señalar que lo catastrófico y monstruoso son tópicos que no dejan de estar presentes en el recorrido que realiza Derrida y que sólo en sus últimas obras se puede ver de forma explícita la vinculación con la democracia, pero desde la postura que se adoptó en el presente escrito se vislumbra la presencia ya en esas primeras publicaciones, lo que posibilita tomar en toda su potencialidad la obra derridiana, no escindiéndola en periodos, sino que a partir de la pesquisa en esas primeras obras se puede enriquecer y valorar la fuerza de la propuesta democrática derridiana para pensar nuestras propias realidades.

\section{Referencias}

BENJAMIN, W. Para una crítica de la violencia y otros ensayos. Madrid: Taurus, 2001.

BENNINGTON, G. Derridabase. En G. Bennington y J. Derrida, Jacques Derrida. Chicago: The University of Chicago Press, 1993.

BISET, E. Violencia, justicia y política: una lectura de Jacques Derrida. Villa María: Eduvim, 2012.

CANGUILHEM, G. La monstruosidad y lo monstruoso. Diógenes. Año IX, octubre-diciembre, $\mathrm{N}^{\circ}$ 40, 33-47. 1962.

DERRIDA, J. Seminario La bestia y el soberano: volumen II: 2002-2003. Buenos Aires: Manantial, 2011.

Seminario La bestia y el soberano: volumen I: 2001-2002. Buenos Aires: Manantial, 2010.

Fuerza de ley: El "fundamento místico de la autoridad. Madrid: Tecnos, 2008.

Cierta posibilidad imposible de decir el acontecimiento. En J. Derrida, S. Gad y A. Nouss, Decir el acontecimiento, ¿es posible? (pp. 79107). Madrid: Arena Libros, 2006.

------ Canallas: Dos ensayos sobre la razón. Madrid: Trotta, 2005.

- Autoinmunidad: suicidios simbólicos y reales. Diálogo con Jacques de Derrida. En Borradori, G. La filosofía en una época de terror: diálogo con Jürgen Habermas y Jacques Derrida (pp. 131-196) Buenos Aires: Taurus, 2004. XXI, 2003.

De la gramatología. Buenos Aires: Siglo

Papel Máquina. Madrid: Trotta, 2003a.

- El siglo y el perdón. Fe y saber. Buenos Aires: Ediciones de la Flor, 2003b.

-------- La tarjeta postal. México D. F.: Siglo XXI, 2001.

- Introducción a "El origen de la geometría" de Husserl. Buenos Aires: Manantial, 2000.

Notas sobre desconstrucción y pragmatismo. En Ch. Mouffe, (comp.) Desconstrucción y Pragmatismo (pp. 151-170). Buenos Aires: Paidós, 1998.

Circonfesión. En G. Bennington y J. Derrida, Jacques Derrida (pp. 25-317). Madrid: Cátedra, 1994. 
Fuerza de ley. El “fundamento místico de la autoridad". Madrid: Tecnos, 1994.

Points de suspension. Paris: Galilée, 1992.

La deconstrucción en las fronteras de la filosofía. Barcelona: Paidós, 1989.

La escritura y la diferencia. Barcelona: Anthropos, 1987.

- Marges de la philosophie. Paris: Les éditions de Minuit, 1972. / Madrid: Cátedra, 1994. FREUD, S. Tótem y tabú. En Obras completas: Volumen XIII (pp. 1-164). Buenos Aires: Amorrortu, 1986.

Lo ominoso. En Obras Completas: Volumen XVII (pp. 215-251) Buenos Aires: Amorrortu, 1986a.

LACOUE-LABARTHE, P. Le sujet de la Philosophie
(Typographies 1). Paris: Aubier-Flammarion, 1979.

- La imitación de los modernos (Tipogra-

fías 2). Buenos Aires: La Cebra, 2010.

- La ficción de lo político. Madrid: Arena Libros, 2002.

MOUFFE, Ch. En torno a lo político. Buenos Aires: F.C.E., 2007.

PLATÓN. Apología de Sócrates. En Obras completas (pp. 49-86) Madrid: Medina y Navarro Editores, 1871.

República. En Diálogos IV (pp. 57-497). Madrid: Gredos, 1986.

Recebido em: $15 / 10 / 2020$

Aprovado em: 15/11/2020 